\title{
Pinterest:
}

\section{Pinning the Gap between SoTL and SLCE in Higher Education}

Amy Burden

Mississippi College

\section{Recommended Citation:}

Burden, A. (2018). Pinterest: Pinning the gap between SoTL and SLCE in higher education. International Journal of Research on Service-Learning and Community Engagement, 6(1), Article 9. 


\title{
Pinterest: Pinning the Gap Between SoTL and SLCE in Higher Education
}

\author{
Amy Burden \\ Mississippi College
}

\begin{abstract}
This article discusses the use of Pinterest as a collaborative reflection and learning tool in a service-learning course at a U.S. university. Social media platforms, such as Pinterest, provide unique opportunities for inclass collaboration; however, these platforms are rarely used by students as processors in higher education service-learning classes. In the methods course discussed in this article, third- and fourth-year students in an ELL certification program taught small groups of English language learners and received mentorship from primary teachers at a local elementary school. They were assigned in-class and peer-to-teacher reflection and collaboration opportunities; however, after instructor review, it was determined that these opportunities did not provide the kind of dialogue necessary to enhance students' knowledge of the course content or of how it applied to the service site. In response, the instructor introduced Pinterest as an educational platform for outside collaboration around activities that connected course content to the objectives laid out for students at the service site. Students pinned, explained, and commented on one another's pins to further student learning. Improvement in student grades suggests the benefit of using Pinterest to enhance students' understanding of course objectives as they related to service. In addition, the communication among students illustrated an example of interactive social media use that could be replicated in other service learning courses in higher education yet has been largely underutilized for this purpose.
\end{abstract}

Keywords: service-learning, social media, Pinterest, higher education, TESOL, teacher education, collaboration, reflection

This article discusses a study conducted around an eight-week reflection assignment developed in a service-learning course for third- and fourth-year students in an English language learner (ELL) certification program. The assignment used Pinterest as a medium for critical reflection on the servicelearning experience, the course objectives, and the relation between the two. Three research questions guided this study:

1. In what ways can Pinterest be used to enhance reflection on service-learning?

2. How can Pinterest be used to enhance collaborative critique of student-created resources and web-based resources for use at service sites?

3. How can Pinterest be used to solidify connections between course content and service?

Though research has shown that students participate actively in social media in the "real world," most social media use in the classroom is decidedly less engaging (Selwyn, 2011). Higher education institutions often lean on traditional methods of instruction, such as lecture; however, as practitioners of service-learning often note, it is difficult to reflect, discuss course content, and address concerns at the service site during a class period using traditional methods of instruction alone. Grasping the pedagogical potential of social media offers service-learning practitioners and their students the opportunity to temper their reflection and participation at the service site with the necessary acquisition of course content, while also connecting with peers outside the learning environment (Dabbagh \& Kitsantas, 2012; McGloughlin $\&$ Lee 2010). The collaborative online reflection assignment discussed here illustrates an efficient method for connecting course content, service-learning, and social media's natural draw for students that was enjoyable for both teacher and students to use. The literature review explores the increasing use of technology for peer review and collaborative learning. The methodology section outlines the research questions, the parameters and setting of the reflection assignment, and participants. Finally, the methods of data collection and discussion sections further highlight Pinterest's potential as a reflective and 
2 | International Journal of Research on Service-Learning and Community Engagement

connective tool in higher education service-learning courses. Suggestions for implementation and further study are also discussed.

\section{Literature Review}

\section{Social Media in Higher Education}

The Internet has grown explosively in the last decade, with social media dramatically changing the ways in which users interact online. No longer is the Internet a one-to-many activity, whereby data are uploaded by relatively few for sharing with the masses; rather, it can now be described as a many-tomany operation, in which the daily activities of its users control the content and interaction with it (Selwyn, 2011).

Social media use in higher education has been well-documented. For example, $33.8 \%$ of college and university faculty use some form of social media in their courses ("Educators' Use of Social Media Evolves," 2013). Faculty from almost every discipline-from fine arts to nursing to math and sciencehave written about the effectiveness of using social media to connect with and teach their students (Drake \& Leander, 2013; Giebelhausen, 2015; McCorkle \& McCorkle, 2012). In fact, instructors are encouraged to enhance their teaching with technology. Selwyn (2011) highlighted three primary reasons for this growning emphasis on social media in higher education: changing students, changing learning styles, and new forms of higher education provision. As Tapscott and Williams (2007) argued, social media is, over time, producing students who are better able to multi-task, have greater social autonomy, and desire authenticity that may go unsatisfied by the older generation's attempts to speak their "lingo." Selwin (2011) maintained that the social media-connected college student tends to be more flexible because of the highly creative and connective environments represented by social media. Thus, it is imperative for practitioners to update traditional reflection methods. Since students are fluent in social media, it seems these platforms are ideal spaces for reflective writing. Instructors can tap into the creativity and connectivity inherent to social media in an effort to advance the cause of service-learning and community engagement (SLCE) and the scholarship of teaching and learning (SoTL).

Indeed, learning has changed because of social media. Students now embrace a "just in time" mentality in relation to information and research which focuses on the immediacy of answers via the internet, changing the way students take in information. Social media has promoted the capacity to know more over the more traditional approach to learning, which emphasizes the accumulation of prior knowledge regarding what is already known (Siemens, 2004). However, there is potential for social media platforms to encourage students' critical thinking and problem-solving skill development (Duffy \& Bruns, 2006).

Social media can also enhance the provision of higher education itself if implemented using student-centered methods. Student-centered use of social media can disrupt the rote nature of traditional teacher-centered classrooms because of its ability to lend greater agency and autonomy to students as active producers - rather than receptive vessels — of knowledge (Lee \& McGloughlin, 2010). For some, using social media in the classroom has become imperative as technology occupies an expanding presence in students everyday lives. More specifically, it connects teachers with their students outside of the traditional classroom and school hours (Heatley \& Lattimer, 2013), while also creating a sense of selfmotivation, which can contribute to positive college learning experiences (Dabbagh \& Kitsanas, 2012; McGloughlin \& Lee, 2010).

One of the main goals of the reflection assignment was to promote collaboration around course content and to determine how it correlated with the service-learning component. Faculty within the arts community have already described social media's role in facilitating and enhancing collaboration. For instance, Sykes (2012) described the welcoming environment created by social media in an advertising course that strengthened collaboration, creativity, and critical thought among students. The author described how the idea of creative flow, the state of being so positively immersed in a project that the creator loses track of time was observed in their project at similar rates to in person collaborative projects. 
Baird and Fisher (2006) compared Vygotsky's (1978) theory on the full social interaction of the learner to optimize cognitive development with social media, noting the latter's ability to "take the social interaction to deeper levels as well as address learning styles rooted in digital technologies" (p. 4). Baird and Fisher called on instructors to develop their curriculum in consideration of traditional theories on adult learnercentered environments while adapting to the realities of the digital age, which has engendered new learning styles (Baird \& Fisher, 2006).

\section{Pinterest}

Pinterest is a social media platform that allows users to create boards of "pins," or digital links to images, web pages, and articles related to topics of interest. It is currently the third largest social media platform, behind Twitter and Facebook ("Learning Sites, References, and Notes," 2012). Recent research has shown that while the average Pinterest account holder is over 40, the majority of active pinners are under 40. Millenials use Pinterest as much as they use Instagram, with $30 \%$ of all social media users logged in to Pinterest (Salam, 2018). The platform is marketed as an educational tool for teachers and administrators in secondary and higher education (Herbert, 2012), namely in the United States, where Pinterest boards have been used regularly by teacher trainers, teachers, and pre-service teachers in the Common Core. In fact, Troutner (2012) listed Pinterest as the site where educators should begin looking for ways to implement Common Core standards in the curriculum. Additionally, Pinterest's collaborative nature has been used for classroom organization, job postings, educator teambuilding, and critiquing webbased and teacher-created resources ("Tools for Schools," 2012).

This article also explores Pinterest's role in facilitating students' learning of course objectives. Heatley and Lattimer (2013) recommended that Pinterest be used as a tool for student access to content and objectives discussed in the classroom. The editors of the journal Tech and Learning advocated for teacher development through Pinterest, noting how specific boards related to teaching and learning can be shared with educators globally for feedback on what works in real-world classrooms ("Using Social Media," 2013). The editors also offered advice for using Pinterest in the classroom, highlighting the ways in which comments on pins add value to the classroom learning experience ("Tips for Using Pinterest," 2015). Likewise, Adams (2012) promoted Pinterest as a tool for educators to critique web-based and teacher-created resources. Speaker Silvia Tolisano cautioned educators not to underestimate the power of Pinterest for classroom use and also advocated for its development as a teaching tool ("Tips for Using Pinterest," 2015).

Students have used Pinterest in higher education; for instance, students in a second-year fashiondesign course collaborated with consumers via Pinterest to create a six-piece "look" direct to the consumer (Lapolla, 2014). However, the platform has been underutilized as a tool for involving students as processors and producers of knowledge. Thus, the current research focused on the need for further engagement with social media sites like Pinterest to produce knowledge.

\section{Student Reflection in Service-Learning}

Reflection is a necessity for personal and academic growth in service-learning (Rama, Ravencroft, Wolcott, \& Zlotkowski, 2000). Critical reflection pushes students to be more accurate when determining the value of a decision, experience, or concept (Alwehaibi, 2012). When students interact in highly reflective service-learning classes, they tend to demonstrate deeper understanding of social issues and how they apply that understanding to the context of the service site. Reflection encourages students to both raise and respond to questions regarding authentic situations at the service site, their caring interactions with others, and the work they produce; in so doing, they derive more from experience (Eyler \& Giles, 1999). Quality reflection engages the teacher in the feedback loop as well, with periodic reflections and comments to correct erroneous assumptions. These teacher comments spur students to become more careful observers, while also allowing the instructor to adjust methods to meet real-time student learning needs (Joint Educational Project [JEP], 2016). Eyler and Giles (1999) conducted interviews with students in service-learning courses and found that while service-learning did impact 
4 | International Journal of Research on Service-Learning and Community Engagement

students' reports of their critical-thinking skills, the quality of service-learning, which included reflection, predicted reports of critical thinking, the ability to perceive consequences of actions, problem identification, and openness to others' perspectives. Eyler and Giles also found that student voices provided instructors with insights into the dynamics of how service-learning contributes to academic learning.

Traditional reflection approaches involving paper journals or learning-management platforms, however, are limiting in several ways. First, valuable individual experiences are typically not shared with the larger group unless the course instructor does so intentionally. Second, traditional sharing methods involve the passing of papers in class, which often takes away from lecture time. Third, the instructor assumes all responsibility for promoting change and growth through feedback (JEP, 2016). Since students are both learners and practitioners in the community being served, it would seem only natural that this duality of roles be visible in the developing feedback loop of reflection (Rama \& Campus Compact, 2001; Sigmon, 1979).

\section{Online Modes of Reflection}

DiGiovanni and Nagaswami (2001) found multiple advantages to online reflection. Teachers may monitor every aspect of the discussion and weigh in equally to each thread. Additionally, students who require more time to process ideas or formulate reflections have equal access to online forums, making online reflection an excellent addition to in-class reflection, which rewards quick thinkers and strong verbal processors. Thus, students maintain greater focus on the task, offering a more accurate indication of student insight into the content and learning (Heatley \& Lattimer, 2013).

Dogan and Robin (2008) examined digital storytelling as a method for presenting the author's voice through narration, music, scripts, video elements, and images. Their study involved teaching inservice instructors how to use the elements and the pedagogy that influence their use, then monitoring teacher and student reactions to their implementation in the classroom. Although not all subjects persisted in their use of digital storytelling for the length of the full study, those who did saw an improvement in technological skills, motivation, and engagement levels.

Walters, Green, Liangyan, and Walters (2011) found that digital reflections more accurately captured the impact of learning experiences than traditional written reflections. Perry et al. (2015) argued that this is because digital platforms often represent discourse communities in which students have knowledge of conventions and a lexis for communicating ideas they might not have access to regarding other reflective tools, thus giving them a louder, clearer voice.

A study conducted at four New England college campuses across multiple concentrations that integrated social media into the curriculum reported the results of a survey on the effectiveness of social media in students' courses. Findings from one portion of the survey that focused on reflective practices showed that $78 \%$ of respodents felt that social media was useful for reflecting on their strengths and weaknesses in a variety of course topics; $81 \%$ agreed that social media use allowed them to reflect on the perspectives of others; and 76\% agreed that social media use required them to apply course concepts to their personal life (Samuels-Peretz, Camiel, Teeley, \& Banarjee, 2017).

Crews and Stitt-Gohdes (2013) conducted a study in a service-learning business communication course that paired students with area nonprofits to craft business letters. The course also required students to create communications for the nonprofits on Twitter and Facebook, which aided the companies involved and allowed for teaching moments regarding social media literacy and the dangers of posting inappropriate materials online. This previous research notwithstanding, there has been very little published on the use of social media in service-learning courses at any educational level. The current study brings the concept into focus with a relevant and innovative pilot program that is easily replicable in larger and more diverse higher education institutions. 


\section{The Study}

My service-learning course is part of an ELL certification program, designed to train students in the implementation of various pedagogies for ELL education. This course partners with a local public school with a moderate population of ELLs but no ELL teacher on staff. The service project that served as the focus for this study paired students with mentor teachers at the school and with small groups of ELLs for instruction throughout the week, based on stated learning needs. (For clarity, I refer to the clients at the service site as "ELLs.") Students in the course were instructed to implement the methods explained in class at the site and to reflect on their experiences in four journal entries, three reflective class periods, and weekly small-group discussions during the first 10 minutes of each class. The mentors met with the students throughout the semester, observed two lessons, and provided feedback.

\section{The Sample}

Participants included third-year, fourth-year, and graduate students. Thirteen of the students were from the United States, and one graduate student was from China. Ten were female and four male; the study was conducted at a college with an overall female population of $61 \%$, so the male-to-female ratio in this course was only slightly below the school's average. Thirteen of the 14 students were Caucasian, a demographic which comprises $80 \%$ of the college's student population. All students were between 19 and 23 years old, an age range in which $73 \%$ of the undergraduate student body fell. The college is small and has a generous student-to-teacher ratio, with $55 \%$ of its classes having fewer than 20 students. The modest sample size also reflected the selectivity of the upper-level teaching certification course, which students typically take after successfully completing three other courses in the program.

All students had taken at least two of the ELL courses in the certification program, and most students were taking this course as their last class. None of the students had prior experience working with diverse learners, though several had completed a service-learning project in another ELL certification course called Multicultural Classroom the previous semester. In that course, students developed and produced a culture fair for a local elementary school that helped the school achieve their common core social studies goals for the year. However, this meant that only half of the students were familiar with service-learning when they signed up for the course. Only the graduate students, who were education majors, came to the class with a grasp on pedagogical theories and methods related to the service site. However, this is not uncommon for the ELL certification program, which is part of a larger TESOL minor. The other students were majoring in English, Foreign Language, and Art. All students used social media to some extent, though only seven students had a Pinterest account. Eight chose to "pin" as part of the elective assignment, although all students accessed the pins.

\section{The Problem}

After responding to individual reflective papers and holding two in-class reflective sessions, I realized that in-class reflection was beneficial and worth greater focus. The students were struggling to connect course content with the service site and were having difficulty applying the theory and methodology to authentic situations in innovative and creative ways. Each class period, students asked for more activities for their ELLs, and I felt a rising tension as students seemed to rely on me completely to make the connection between service-learning and the methods being discussed. For example, in a reflection paper, one student wrote:

With regards to the service learning this semester, the classroom and the service learning should be more connected. When I learned the material in the classroom it hardly, if ever, related to the activities and needs of the students I was teaching.

I spent hours on Pinterest searching for activities for my students that matched both their needs and the pedagogical methods I was teaching. I then presented the ideas to the class; typically, the activities would benefit one or two students, leaving the rest to think, "But what about my ELLs?" It 
6 | International Journal of Research on Service-Learning and Community Engagement

became obvious that the students were relying too heavily on me to make critical connections for them, and when I did not make the connections explicit, the students oftentimes exhibited frustration and disatisfaction at the service site. I needed to find a way for students to understand that service-learning is a process of discovery, effort, success, and failure. They needed to connect classroom methods to their respective ELLs' needs. I could no longer play the authoritative sage and they the passively receptive vessels. Therefore, I began encouraging the use of Pinterest for establishing key connections between the service site and the methods taught in the course. I also encouraged the students to comment on the pins and upload their own work so that they could take the 10- to 15-minute small-group reflections held at the beginning of class outside the classroom and onto social media, where they congregated regularly.

I also realized that the information I was giving in the personal feedback loop was relevant to more than each original writer. I wanted all students to have access to the resources I found to assist individuals. My students also desired to share lessons that worked and to advise one another as they learned of critical incidents at the service site. Therefore, I recommended that students pin web-based resources and student-created resources they had used at the site, and offered ideas about pinning articles that described the site, its challenges, and students' thoughts on them. For instance, they could pin pictures and memes that explained concepts such as social justice and educational inequality. As students pinned, I monitored and added to the board. For each pin, students received one extra-credit point on a past homework assignment. If they described the pin using Accountable Talk (described in detail in the Methods section), they received an additional extra-credit point on a previous homework assignment. I found that Pinterest could serve as an excellent means for dispensing current news in the field and promoting diverse perspectives on topics like state testing, immigration, ELL support, and language ideologies in the classroom. I added articles from current-events websites related to the curriculum and took time in class to remind students of the pinning process, the extra-credit opportunities, and recent pins they should focus on to stay updated and informed.

\section{The Purpose}

The purpose of this study was to foster greater peer collaboration than the in-class reflections allowed. It also sought to improve students' access to resources and materials focused on learning objectives and strategies for teaching ELLs in ways that promoted peer review and feedback. When students uploaded their own pins, they were effectively submitting their work for peer review. They had done this multiple times in the classroom environment, and it had seemed to facilitate the discovery that comes with learning through service. When students commented on each other's pins, they engaged in providing both feedback and reflection. A final goal for students was to solidify the connections between the servicelearning experience and the course-content objectives, allowing for review, feedback, discussion, and sharing in a less intimate and formal setting, where research shows students are more likely to share more freely (Lee \& Kim, 2014).

\section{Data Collection}

I took observational notes in class and read through formal reflection papers and assessments, which served as qualitative data sources for the study. However, the main data source was quantitative: To determine the level of student participation in the assignment, I performed a tally of pins and the number of registered users. Over the course of eight weeks, eight of the 14 registered users made a total of 65 pins (or an average of eight pins per user), with a maximum use of 27 pins and a minimum use of one pin. To determine the level of collaboration, I categorized the types of resources pinned, the descriptions, and the comments using a checklist for Accountable Talk and the DEAL model (described in a later section) to determine reflectivity of pins. 


\section{Accountable Talk}

Michaels, O'Connor, and Resnick (2008) described Accountable Talk as a communication strategy whereby a student gives their opinion directly to another student (as opposed to the teacher) using the student's first name; the opinion may agree or disagree with the student being spoken to, and evidence is provided to support the opinion. This method is used in primary and secondary education to facilitate greater student-to-student interaction and critical thinking. (I have used Accountable Talk successfully for peer review in other classes on Facebook; see Burden, 2016 for more details). On Pinterest, direct communication with another pinner takes the form of a comment on a pin. In this context, stating the pinner's name is redundant, so I did not consider this factor when coding for uses of Accountable Talk. Pinterest changes the conversational ettiquette somewhat on how someone can share an opinion; that is, the platform encourages the removal of hedging devices, such as "I think," "kind of," and "maybe," in favor of more direct advising of fellow pinners. On Pinterest, each pinner assumes the voice of an expert since it is primarily an idea-sharing site. I therefore looked for use of common language around Accountable Talk as described by the South Nevada Regional Professional Development Program (SNRPDP) in their free Accountable Talk teacher toolkit. Figure 1 comprises a checklist identifing the types of language needed to be considered Accountable Talk on the classroom Pinterest board.

Figure 1. Checklist of Accountable Talk for pin comments. Adapted from the Accountable Talk toolkit (SNRPDP, n.d.)

Make use of specific and sound knowledge by referencing course materials, past lectures, or personal experiences at the service site.

$\square$ Construct explanations for the inclusion of pins and acknowledge where more information is needed

$\square$ Formulate hypotheses and conjecture with suggestions on how to try ideas at the service site

$\square$ Provide reasons for claims as well as create hypothetical scenarios and examples to support conclusions regarding pins.

$\square$ Reference knowledge built in the classroom to provide evidence for claims and arguments. Employ evidence from the service site to back up explanations.

\section{DEAL Model}

In reading comments and coding for reflection, I used Ash and Clayton's (2004) description, examination, and articulation of learning (DEAL) model. This model operates around three questions: Does the writing describe the experience objectively? Is there an examination of experiences through learning goals? Does the student articulate goals for future action for improved practice and refinement of learning? If a pin represented a response to any of the model's three questions, it was considered reflective. Based on the DEAL model, four types of pins were categorized: pins specifically related to course content objectives (E), pins related to service-learning and/or the service site (D), student-created resource-sharing pins (E, A), and web-based resource-sharing pins (also E, A).

\section{Results}

Sixty-five pins contained student-written descriptions, and two critical comments were made. Fifty-two pins $(80 \%)$ related to course content objectives; 12 (18.4\%) related to both service-learning and content objectives; five (7\%) described student-created resources for use at the service site; and 47 (72\%) described web-based resources for use at the service site. Additionally, the Accountable Talk checklist determined that 28 descriptions and comments (43\%) used accountable talk. Figure 2 indicates the types and quantites of pins posted by participants. 
Figure 2. Types and quantities of pins posted by students.

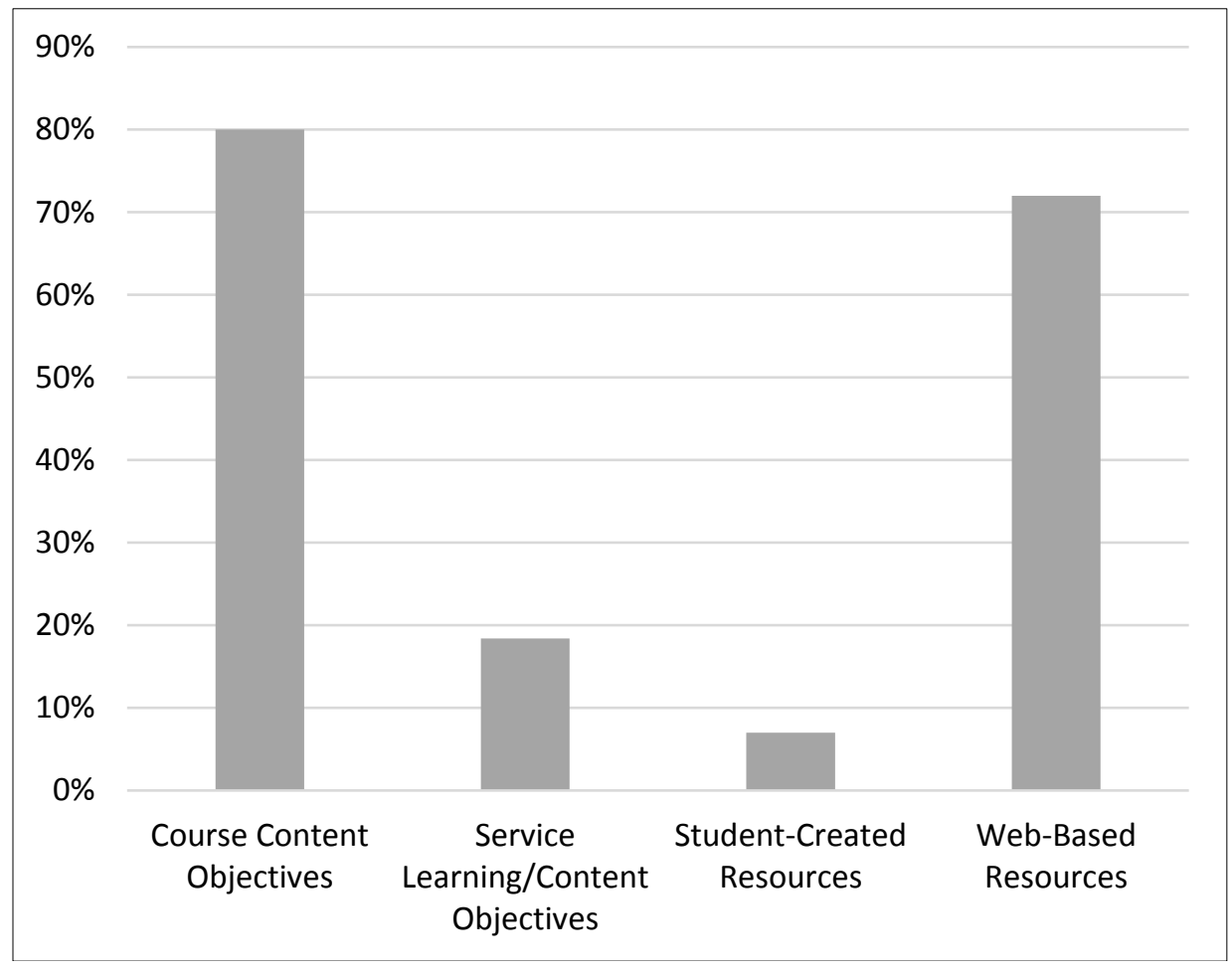

Analysis of grades on content-related homework assignments was conducted before the introduction of Pinterest and after. The average participant score before the use of Pinterest was $80.93 \%$, with a median score of $90 \%$. The average participant score after the introduction of Pinterest was $91.40 \%$, with a median score of $90 \%$. The average non-participant score (taken as a control) after the introduction of Pinterest was $86.14 \%$, with a median score of $90 \%$.

\section{Discussion}

Pinterest shows promise as a teaching and learning tool in higher education. In this study, participant scores increased by $10 \%$ after the implementation of Pinterest as a tool to connect content and applications of service-learning. Students who chose not to make pins (despite having access to the board) showed a smaller increase (6\%) in content-based assignment scores. Eighty percent of pins connected some aspect of the course content to the service-learning site. This suggests that students used Pinterest as a method for processing and producing knowledge on either course content or the service site outside of class. Additionally, since the course ended, four students have continued accessing the resources pinned by their peers. One former student reported that during her new teaching career, she had referred to the web-based pins of her peers in developing her lessons. Because of the relational nature of Pinterest, collaboration between students increased from the three in-class cooperative experiences to 65 out-ofclass pins.

\section{In What Ways Can Can Pinterest Be Used to Enhance Reflection on Service- Learning?}

Over $18 \%$ of pins related to out-of-class reflection on service-learning. However, there is still work to be done within the course to promote quality reflection on serving, learning, and knowledge using Pinterest 
to verify the claim that it enhances rather than simply increases reflection. One student pinned the following comment on the class board:

As an introductory activity for my colors lesson plan, I used this YouTube video about colors using ducks. This video was helpful because it presented the vocabulary the students need to know for the lesson while also keeping their attention and providing some entertainment.

This comment meets the standards of Accountable Talk and reflection on student performance at the service site. The student shares an example of authentic comprehensible input, gives their opinion on the effectiveness of the resource, and reflects on their time at the service site by providing information on how the children reveived the resource. Another student pinned the following comment:

The week after Valentines Day, I included this worksheet in my lesson about punctuation. The students enjoyed the hands on project, and it was an efficient way to assess their understanding of the material, which was an integral part of any lesson plan.

This comment shows that the student reflected on their time at the site by examining the children's reactions to the lesson through goals (the $\mathrm{E}$ in the DEAL model). The student also used reflection to defend the stated opinion on the usefulness of the lesson plan, a characteristic of Accountable Talk. As another student pinned,

[The teacher] already shared this, but I think it needs to be brought back.... I just read the whole article. It really really says some hard truth. It can be hard to read and think about, but I believe it is true. Think about this as you reflect on social justice vs charity. Also, I think it's good to remember that "social justice" in this instance is not talking about how it's the government's job to regulate and enforce. However, it's our job!

This student reflects directly on their role at the service site in sharing the article with the group. The student provides background on the article and gives advice to others who may be grappling with similar questions of what role they are filling at the service site (the E in the DEAL model).

\section{How Can Pinterest Enhance Critique of Student-Created Resources and Web- Based Resources for Use at the Service Site?}

Five pins described student-created resources, 47 described web-based resources, and 28 used Accountable Talk to critique the resources. Forty-three percent of pins showed elements of critical thought backed up by evidence taken from lectures, experiences at the service site, and/or the textbook. These data suggest that Pinterest was employed to critique resources for use at the service site, with an emphasis on web-based resources. However, Pinterest's capacity as a tool for provided peer feedback regarding student-created resources was, at best, underused by students. As one student commented, "This could be a great poster or handout to give students to encourage them to assess themselves and for the teacher to understand which concepts to focus on in future lessons." Here, the student shares a resource that may benefit other student teachers for assessment purposes, a unit covered in the curriculum, and a daily activity at the service site. The following comment about web resources demonstrates critical thought regarding their usefulness to the pre-service teacher and the children served: If you are looking for a way to incorporate student self-assessment, or just checking assessment with the student, this worksheet would be resourceful since the students would be able to see their progress and visualize what they need to work on while showing the teacher which shapes have been learned.

Use of phrases like "since the students" exemplifes ways that comments were used as explanations in critique of web-based resources, a characteristic of Accountable Talk. Similarly, another student pinned, When teaching my students the alphabet, I used worksheets like this to allow the students to color the pictures and relate the letters to the images. While coloring the pictures, I would have the 
10 | International Journal of Research on Service-Learning and Community Engagement

students say the names of the pictures aloud and spell each word aloud which provides not only a visual representation but also vocal and auditory practice.

Here, the student reflects on materials used, explains the process, and gives a reason for their choice by refering to a lecture on diverse learning styles.

\section{How Can Pinterest Solidify Connections Between Course Content and Service?}

Fifty-two pins related to course content objectives, suggesting a desire to use Pinterest to connect the content with the service site. Students' verbal feedback indicated that Pinterest was an asset in building confidence in the resources they took to the site and in their own abilities to create innovative activities to enhance learning. As one student reflected, "To plan lessons so far, I have relied heavily on blogs and such that explain how to work with and engage distracted students, Pinterest, and talking to my elementary ed friends." Student assignment scores increased $6 \%$ for those who did not pin and $10 \%$ for those who actively pinned. This different could be attributable to the connection of content objectives and their applications at the service site through Pinterest. One student pinned, "This is a neat graphic organzier. We could maybe use this in the writing lesson plan for a YouTube video of an episode." Here, the student is preparing to write their lesson plan to be turned in and graded. The student suggests to the group that this source matches the methodologies on teaching writing discussed in class. Another student commented,

This is a cool letter organizer that we can use in the Writing Lesson Plan, in the Writing Stage. Maybe you could talk through what they want to write and then help them write each word. It would take a long time, but they would end up with a whole letter.

Similarly, this student found a resource they felt matched the methods discussed regarding teaching second-langauge writing. The student then goes on to provides more details about how a pre-service teacher would use course methods with the resource to create an activity for one stage in the writing process. Another student critiqued a website related to course content and commented on how it could be applied at the service site:

This site addresses the need for teachers to implement more socially aware concepts into their lessons in order to promote social justice within the classroom. It's a great resource for future teachers as it provides examples of practical applications that could be used in the classroom.

Additionally, students who scored a $\mathrm{C}$ or lower in the class and those who achieved a B or higher saw an increase in their assignment scores. This suggests that student connections between SLCE and SoTL can be improved using Pinterest with proper explanation, motivation, and consistent reference to the benefits of participation. Pinterest appears to have a low barrier to entry; registration is simple, and it is easy to follow a board. Students did not have to create pins in order to be silent participants.

Additionally, for many, the ease of searching for pins on specific needs lowered the barrier to using it as a primary source for connecting in-class methods with service site needs. Academic ability did not seem to affect student participation. Gender, however, seemed to play a role, as females tended to be more excited about using the platform than males, with only one of the four men in the class participating online. This seems reflective of the global statistic that $81 \%$ of Pinterest users are female (Aslam, 2018).

\section{Conclusion}

While Pinterest shows promise as a tool for collaboration in higher education classrooms, there is still considerable room for improvement and refinement in its implementation - and analysis and research of it. I learned several lessons through trial and error. For example, Pinterest automatically publishes a board publicly; that is, the creator must designate it as private when creating the board. Boards created publicly cannot be changed to private boards later. This can cause privacy issues for students and for the instructor as a private individual. Therefore, instructors should register a Pinterest account for business 
use. They can also encourage students to sign up for an account for business use to protect their privacy going forward, since once a person is "followed," they share access to everything pinned on a public board. Thus, the instructor should make the class board private at creation to allow for maximum privacy.

Ruoxu, Fan, Saijing, and Shyam (2016) reported that commenting is the least utilized function of Pinterest. As confirmation of this, only two pins in my course commented on a student-created resource, showing that peer review was under-used though available. Helping to intrinsically motivate students to pin, describe, and comment on pins may increase participation. In a study by by D'Lima, Winsler, and Kitsantas (2014), college students had significantly higher levels of intrinsic motivation than extrinsic motivation during their first year of school. Influencing students through intrinsic motivation may be the key to greater involvement.

Dasha (2017) produced a list of activities shown to intrinsically motivate college students. Based on that list, I developed the following strategies for instructors around using Pinterest in the servicelearning classroom:

- Identify good descriptions as those that efficiently use Accountable Talk to critique a resource in order to build students' self-esteem and self-confidence regarding their Pinterest literacy among their peers.

- Be honest with students about what counts as successful communication.

- Encourage greater collaboration through pinning by creating a competitive atmosphere for those who pin and those who pin and comment or reply.

- Make a consistent effort to talk about the benefits of pinning, reviewing, and commenting on others' pins since this could increase participation (Dasha, 2017).

Despite its relative ease of use, Pinterest still presents a learning curve for some students. Thus it may be helpful for instructors to develop a student tutorial for using Pinterest, including examples of how to upload original work, comment, and critique. According to Ryan Pinkham, from the marketing firm Constant Contact, before someone signs up for Pinterest, they should know what it is and have a goal in mind for using the platform. Three students in the course reported that they had never used Pinterest before. These students chose not to participate in the assignment because they did not think they had the time to learn to use Pinterest outside of class. This was not a form of social media they already used, and my incentives for pinning did not motivate them to learn. As Salam (2018) reported, 75 billion ideas have been uploaded to Pinterest to date, but $93 \%$ of active pinners use Pinterest for consumer purposes, making the educational benefits of the platform far less obvious to millenial learners than previously expected.

\section{Implications}

The results of this study suggest that Pinterest can serve as a means for helpting to bridging the gap between service and learning. With $18.4 \%$ of pins in the study containing reflective elements, Pinterest can be used to increase student reflection on service-learning. The ability of students to comment on pins of web-based resources and to reply to comments lends Pinterest unique educational potential that has not been tapped in most higher education classrooms. Combining these functions with the students' own uploaded resources augments their reflective and collaborative capabilities. Within the right context, teachers could replace certain traditional reflection methods with pins, comments, and replies, thereby giving students more opportunities to interact and reflect cooperatively.

The study results also demonstrate Pinterest's unique ability to connect students with experts in the field through resource sharing. Forty-three percent of pins revealed students' critical thought on these resources using Accountable Talk. By teaching students how to comment on pins effectively, Pinterest can be used to develop and practice critical-thinking skills within the service-learning environment, a necessity for applying theory to authentic service scenarios.

Finally, this article centers on Pinterest's ability to "pin the gap" between SLCE and SoTL. Ninety-three percent of pins in the study related to course objectives, demonstrating the low barrier to connecting resources for the service site to the course. This is one of SLCE's biggest obstacles. How do educators help students make these connections without sacrificing the quality of the curriculum? How 
can educators monitor students' connections? Pinned resources and comments on pins regarding course objectives can represent a means for observing students make those connections. Even if Pinterest is not used as a replacement for traditional methods, its ability to connect students with one another and to course material makes it a useful (and free) resource for the higher education classroom.

Despite the small sample size, the pilot study represented an ideal opportunity to examine the use of Pinterest for reflection in a service-learning classroom, explore uncharted use of social media, and identify areas for more extensive research. This research represents a good first step toward investigating the usefulness of Pinterest and provides a precedent for future research across a larger spectrum, potentially at multiple universities.

\section{Limitations and Suggestions for Further Research}

This research used very little qualitative data to understand students' opinions of Pinterest. Therefore, more information could be gathered from interviews, reflection journals, and surveys (for instance) to produce a more robust dataset around the topic. Future research could gather student feedback on the validity of using Pinterest over other forms of social media. Gathering a list of pros and cons from students on the use of Pinterest for collarboration and reflection would also generate other considerations for future research. Additionally, while increases in student scores were reported after the implementation of the Pinterest assignment, it is not certain if these increases were solely the result of Pinterest use. More qualitative data (perhaps in the form of journalling) might reveal to what extent the increases in scores were attributable to Pinterest. The average Pinterest user spends only 14.5 minutes per day on the platform (Salam, 2018). How does this limited daily usage affect the quality of reflection and peer review in the context of the service-learning classroom? Would this average be similar to the average for educators, student teachers, and students of higher education? Finally, research using larger sample sizes should be conducted to determine other factors that may limit or broaden the use of Pinterest for these purposes. A more diverse group of learners - including minority learners, second-language learners, and nontraditional students - may have varying perspectives on the usefulness of Pinterest and would make focuses for future studies. Finally, examining students who are more experienced with either service-learning or within the academic discourse community of the course may yield notable differences.

\section{Author Note}

Amy Burden, Modern Languages, Mississippi College.

The author is now affiliated with the University of Memphis.

Correspondence regarding this article should be addressed to Amy Burden, Teaching Assistant, Department of English, University of Memphis, Memphis, TN 38152. Phone: (901) 678-2651.

\section{References}

Adams, C. (2012). The connected class. Scholastic Parent and Child, 20(3), 16.

Alwehaibi, H. U. (2012). Novel program to promote critical thinking among higher education students: Empirical study from Saudi Arabia. Asian Social Science, 8(11), 193-204.

Ash, S., \& Clayton, P. (2004). The articulated learning: An approach to reflection and assessment. Innovative Higher Education, 29(2), 137-154.

Aslam, S. M. (2018). Pinterest by the numbers: Stats, demographics \& fun facts. Retrieved from https://www.omnicoreagency.com/pinterest-statistics

Baird, D. E., \& Fisher, M. (2006). Neomillennial user experience design strategies: Utilizing social networking media to support "Always On" learning styles. Journal of Educational Technology Systems, 34(1), 5-32.

BBC Active. (2010). Using Pinterest for education. Retrieved from http://www.bbcactive.com/BBCActiveIdeasandResources/UsingPinterestforEducation.aspx

Burden, A. (2016). Three methods to enhance peer review in your classroom. The Teaching Professor, $30(10), 1$. 
Crews, T., \& Stitt-Gohdes, W. (2013). Using social media to develop business communication skills in a service-learning setting. Journal of Research in Business Education, 55(1), 53-68.

Dabbagh, N., \& Kitsantas, A. (2012). Personal learning environments, social media, and self-regulated learning: A natural formula for connecting formal and informal learning. Internet and Higher Education, 15(1), 3-8.

Dasha. (2017). How to spark intrinsic motivation in your students. Retrieved from https://teach.com/blog/how-to-spark-intrinsic-motivation-in-your-students/

DiGiovanni, E., \& Nagaswami, G. (2001). Online peer review: An alternative to face-to-face? English Language Teaching Journal, 55(3), 263.

D'Lima, G. M., Winsler, A., \& Kitsantas, A. (2014). Ethnic and gender differences in first-year college students' goal orientation, self-efficacy, and extrinsic and intrinsic motivation. Journal of Educational Research, 107(5), 341-356. doi:10.1080/00220671.2013.823366

Dogan, B., \& Robin, B. (2008). Implementation of digital storytelling in the classroom by teachers trained in a digital storytelling workshop. In K. McFerrin, R. Weber, R. Carlsen, \& D. Willis (Eds.), Proceedings of the Society for Information Technology \& Teacher Education International Conference (pp. 902-907). Chesapeake, VA: AACE. Retrieved from http://editlib.org/p/27287/

Drake, M. A., \& Leander, S. A. (2013). Nursing students and Ning: Using social networking to teach public health/community nursing in iBaccalaureate nursing programs. Nursing Education Perspectives, 34(4), 270-272.

Duffy, P., \& Bruns, A. (2006). The use of blogs, wikis and RSS in education: A conversation of possibilities. In Proceedings of the Online Learning and Teaching Conference 2006 (pp. 31-38). Brisbane, Australia.

Educators' use of social media evolves. (2013). BizEd, 12(1), 64.

Eyler, J., \& Giles, D.E. (1999). Where's the learning in service-learning? San Francisco: Josey-Bass.

Giebelhausen, R. (2015). What the tech is going on? Social media and your music classroom. General Music Today, 28(2), 39-46. doi:10.1177/1048371314552523

Heatley, E. R., \& Lattimer, T. R. (2013). Using social media to enhance student learning. Techniques: Connecting Education and Careers, 88(1), 8-9.

Herbert, M. (2012). Pinterest: The newest social media phenomenon. District Administration, May, 75.

Joint Educational Project Center for Service Learning. (2016). Reflection. Retrieved March 12, 2016, from https://dornsife.usc.edu/joint-educational-project/reflection/

Lapolla, K. (2014). The Pinterest project: Using social media in an undergraduate second year fashion design course at a United States university. Art, Design and Communication in Higher Education, 13(2), 175-187. doi:10.1386/adch.13.2.175_1

Lee, J. H., \& Kim, H. (2014). An exploratory study on the digital identity formation of Korean university EFL learners. English Teaching: Practice and Critique, 13(3), 149-172.

Lee, M., \& McGloughlin, C. (2010). Web 2.0-based e-learning. Hershey, PA: Information Science Reference.

Learning sites, references, and notes. (2012). Public Library Quarterly, 31(3), 281-284. doi:10.1080/01616846.2012.707113

McCorkle, D. E., \& McCorkle, Y. L. (2012). Using LinkedIn in the marketing classroom: Exploratory insights and recommendations for teaching social media/networking. Marketing Education Review, 22(2), 157-166.

McGloughlin, C., \& Lee, M. J. W. (2010). Personalised and self-regulated learning in the Web 2.0 era: International exemplars of innovative pedagogy using social software. Australasian Journal of Educational Technology, 26(1), 28-43.

Michaels, S., O'Connor, C., \& Resnick, L. (2008). Deliberative discourse idealized and realized: Accountable Talk in the classroom and in civic life. Studies in Philosophy and Education, 27(4), 283-297. doi:10.1007/s11217-007-9071-1 
14 | International Journal of Research on Service-Learning and Community Engagement

Perry, L., Stoner, L., Schleser, M., Stoner, K. R., Wadsworth, D., Page, R. \& Tarrant, M. A., (2015). Digital media as a reflective tool: Creating appropriate spaces for students to become introspective. Compare: A Journal of Comparative and International Education, 45(2), 323-330. doi:10.1080/03057925.2014.993237

Pinkham, R. (2018). 10 things you need to do when getting started on Pinterest. Retrieved from https://blogs.constantcontact.com/getting-started-on-pinterest/\#

Rama, D. V., \& Campus Compact. (2001). Reflection: Intercultural border crossing, power, and priviledge. Retrieved March 11, 2016, from https://compact.org/globalsl/toolsandsyllabi/reflection-intercultural-border-crossing-power-and-privilege

Rama, D. V., Ravencroft, S. Wolcott, K, \& Zlotkowski, E. (2000). Service-learning outcomes: Guidelines for educators and researchers. Issues in Accounting Education. 15(4), 656-689.

Ruoxu, W., Fan, Y., Saijing, Z., \& S. Shyam, S. (2016). Why do we pin? New gratifications explain unique activities in Pinterest. Social Media + Society, 2(3). doi:10.1177/2056305116662173

Salam, M. (2018). Pinterest by the numbers: Stats, demographics \& fun facts. Retrieved from https://www.omnicoreagency.com/pinterest-statistics/

Samuels-Peretz, D., Dvorkin Camiel, L., Teeley, K., \& Banerjee, G. (2017). Digitally inspired thinking: Can social media lead to deep learning in higher education? College Teaching, 65(1), 32. doi:10.1080/87567555.2016.1225663

Selwyn, N. (2011). Social media and higher education. In The Europa World of Higher Learning 2012. London: Routledge. Retrieved from http://www.educationarena.com/pdf/sample/sample-essayselwyn.pdf

Siemens, G. (2004). Connectivism: A learning theory for the digital age. Retrieved October 24, 2016, from http://www.itdl.org/journal/jan_05/article01.htm

Sigmon, R. (1979). Service-learning: Three principles. Synergist, 8(1), 9-11.

South Nevada Regional Professional Development Program. (n.d.). Accountable Talk toolkit. Retrieved from http://rpdp.net/admin/images/uploads/resource 11524.pdf

Sykes, J. (2012). Locating the value and opportunities for online collaborative creativity within advertising. Art Design \& Communication in Higher Education, 11(2), 91-109.

Tapscott, D., \& Williams, A. (2007). Wikinomics. New York: Atlantic.

Tips for using Pinterest in the classroom. (2015). Tech \& Learning, 35(12), 12.

Tools for schools. (2012). Curriculum Review, 51(6), 4-5.

Troutner, J. (2012). Common Core, content creation, and curriculum. Teacher Librarian, 40(2), 48-50.

Using social media as a professional learning tool. (2013). Tech \& Learning, 34(3), 32-34.

Vygotsky, L. S. (1978). Mind in society: The development of higher psychological processes. Cambridge, MA: Harvard University Press.

Walters, L., Green, M., Liangyan, W., \& Walters, T. (2011). From heads to hearts: Digital stories as reflection artifacts of teachers' international experience. Issues in Teacher Education, 20(2), 37 52. 